\title{
Late-Onset Spondyloarthritis: Subset That Should Not Be Forgotten
}

The spondyloarthritis (SpA) complex embraces ankylosing spondylitis (AS), reactive arthritis $(\operatorname{Re} A)$, psoriatic arthritis (PsA), arthritis related to inflammatory bowel disease (IBD), and forms that do not fulfil established criteria, which are labelled as undifferentiated SpA (uSpA) ${ }^{1,2}$. In the early 1990s, 2 sets of classification criteria were suggested to encompass the clinical spectrum of SpA: the Amor criteria $^{1}$ and the European Spondylarthropathy Study Group $(\mathrm{ESSG})^{2}$ criteria.

Each form of SpA may have a late onset ${ }^{3,4}$. The onset of AS, as defined by the modified New York criteria ${ }^{5}$, is unusual after the age of 50 years. In a population-based descriptive study carried out in Rochester, Minnesota, USA, the total incidence rate of AS was 7.3 per 100,000 person-years and the incidence value after age 55 years was $2.2 / 100,000$ per year ${ }^{6}$. In a survey of a large number of members of the German Ankylosing Spondylitis Society, only 6\% had the beginning of symptoms after age 40 years ${ }^{7}$. Only a few studies have compared the clinical expression of late-onset disease with that of earlier onset. In 2001, Brophy and Calin examined the influence of age at symptom onset on disease expression as measured by BASRI (Bath AS Radiology index), BASDAI (Bath AS Disease Activity Index), BASFI (Bath AS Functional index), percentage undergoing AS-related surgery, and prevalence of extraarticular manifestations (uveitis, psoriasis, IBD) in patients with earlier onset (before 21 years of age) and late onset (after 30 years of age $)^{8}$. Age at onset had no significant effect on radiological progression, disease activity, need for non-hip surgical intervention, and prevalence of extraarticular manifestations. In contrast, there was a significant increase in frequency of hip involvement and total hip replacement in patients with early-onset disease. Regardless of age at onset, radiological spinal progression was greater in those with hip involvement than in those without. Previously, the same group reported that shoulder involvement was more common in patients with AS with age at onset between 35 and 45 years compared with those with age at onset between 20 and 25 years 9 .

In the May issue of The Journal, Montilla and coworkers report the results of their comparative study of late- versus early-onset $\mathrm{AS}^{10}$. A total of 1257 patients meeting the modified New York criteria for AS enrolled in the prospective National Registry of Spondyloarthritis of the Spanish Society of Rheumatology (REGISPONSER) database were evaluated. Patients with psoriasis and IBD were excluded. Forty-four (3.5\%) out of the 1257 had disease onset at age $\geq 50$ years. The late-onset group showed a significantly higher frequency of neck involvement and peripheral arthritis of the upper and lower limbs, both at the beginning and during the course of the disease. No important differences in genetic expression, disease activity, or radiological progression were found between the 2 groups.

Late-onset uSpA seems to be comparatively more common than late-onset $\mathrm{AS}^{3,4}$. The first study drawing attention to late-onset uSpA was published in 1989 by Dubost and Sauvezie ${ }^{11}$. They described the case histories of 10 HLA-B27-positive men who developed oligoarthritis and a large area of inflammatory pitting edema of the lower extremities after age 50 years. These patients showed unexplained constitutional symptoms, together with high levels of acute-phase reactants and mild involvement of the axial skeleton. Response to nonsteroidal antiinflammatory drugs (NSAID) was inadequate, and symptoms persisted from one to several years. Nine patients met the Amor criteria for $\mathrm{SpA}$ at diagnosis. Five patients developed sacroiliitis during followup, and 4 of these satisfied criteria for AS. The authors differentiated their late-onset peripheral SpA from the RS3PE syndrome (remitting, seronegative, symmetrical synovitis with pitting edema) described by McCarty, et al ${ }^{12}$. In 1991, Dubost, et al reviewed the files of male patients who had been hospitalized over a period of 12 years for a rheumatoid factor-negative arthritis beginning after the age of 50 years $^{13}$. Patients with polymyalgia rheumatica (PMR), crystal-induced arthritis, or psoriasis were excluded. Of the 105 patients, 29 met American College of Rheumatology criteria for rheumatoid arthritis, 29 the New York criteria for AS, 3 had ReA, and 44 had unclassified arthritis. Fourteen of the 44 were positive for HLA-B27. Most of these last patients had

See Clinical features of late-onset vs early-onset AS, page 1008 of the May issue

Personal non-commercial use only. The Journal of Rheumatology Copyright @ 2012 . All rights reserved. 
oligoarthritis, together with inflammatory pitting edema, marked constitutional symptoms, and elevated erythrocyte sedimentation rate, suggesting that late-onset uSpA may occur mostly with this pattern.

In order to delineate the clinical spectrum of late-onset uSpA, we studied all consecutive patients older than 45 years at onset of the first symptom of SpA not meeting criteria for any of the definite categories of SpA and seen in a 5 -year period ${ }^{14,15}$. Twenty-three patients $(11$ men and 12 women; 17 HLA-B27-positive and 6 negative) were seen in the study period. Of these, 12 had 3 or more clinical manifestations of SpA including peripheral enthesitis, peripheral arthritis, dactylitis, inflammatory spinal pain, buttock pain, chest wall pain, acute anterior uveitis, heart involvement, and sacroiliitis. Seven patients showed 2 manifestations and 4 only one. Only 10 out of the 23 patients had peripheral arthritis, 3 of whom had ankle or tarsus involvement, together with the large inflammatory pitting edema described by Dubost and Sauvezie ${ }^{11}$. Of the 2 patients with only one manifestation, one had acute anterior uveitis and one peripheral enthesitis. Of the 23 patients, only 15 met the Amor ${ }^{1}$ and/or the $\mathrm{ESSG}^{2}$ criteria for SpA, suggesting that more sensitive criteria are desirable. The conclusion of the study was that inflammatory pitting edema is not always present and that the clinical spectrum of uSpA is as broad in the elderly as it is in children and young and middle-aged adults. We found similar results examining another series of 20 consecutive patients with HLA-B27-positive late-onset $\mathrm{uSpA}^{16}$. Interestingly, 3 out of 20 patients had a PMR-like syndrome at onset, suggesting that PMR should be taken into consideration in the differential diagnosis ${ }^{16,17}$.

Recently, the Assessment of SpondyloArthritis international Society (ASAS) developed and validated criteria for axial and peripheral SpA that will take the place of the Amor and ESSG criteria ${ }^{18,19}$. Axial criteria (in addition to AS criteria as defined by the New York criteria as structural damage on pelvic radiographs) can also include the nonradiographic phase of sacroiliitis in which inflammation can be detected by magnetic resonance imaging (MRI) as bone-marrow edema and osteitis ${ }^{18}$. According to these criteria a patient with back pain of at least 3 months' duration and with age at onset of symptoms less than 45 years can be classified as having axial SpA if there is imaging evidence of sacroiliitis on pelvic radiographs or on MRI, plus one of the following SpA features: inflammatory back pain, arthritis, enthesitis (heel), uveitis, dactylitis, psoriasis, IBD, good response to NSAID, family history of SpA, HLA-B27 positivity, and elevated C-reactive protein. A patient with no imaging evidence of sacroiliac joint involvement but who is positive for HLA-B27 should have 2 of the above SpA features. These classification criteria will be used extensively in clinical and epidemiological studies in the near future and have also replaced the modified New York criteria in the ASAS recommendations for the beginning of anti-tumor necrosis factor (TNF) therapy ${ }^{20}$. As a result, it is now also possible to treat patients with TNF inhibitors in the nonradiographic phase of sacroiliitis. As for the criteria for peripheral SpA, the patient should have arthritis or enthesitis or dactylitis plus one of the following $\mathrm{SpA}$ features: uveitis, psoriasis, IBD, preceding infection, HLA-B27 positivity, and sacroiliitis on imaging; or 2 of the following features: arthritis, enthesitis, dactylitis, IBD, and family history of $\mathrm{SpA}^{19}$. These criteria cover most of the clinical spectrum of SpA including ReA, PsA, IBD-related SpA, and uSpA. However, these criteria should be validated in late-onset uSpA since only $15 \%$ of study patients were older than 45 years at the disease onset.

In conclusion, the ASAS criteria for axial and peripheral SpA need to be validated in late-onset patients with axial disease and uSpA. With longer life expectancy it is highly likely that these patients will be seen more and more frequently in rheumatology outpatient clinics. Patients with late-onset SpA need to be included in clinical trials and epidemiological studies. In addition, late-onset patients with axial SpA should be treated with anti-TNF early in their disease, similarly to patients with earlier disease onset.

\author{
IGNAZIO OLIVIERI, MD, \\ Consultant, Director, \\ Rheumatology Department of Lucania, \\ San Carlo Hospital of Potenza and Madonna \\ delle Grazie Hospital of Matera, \\ Potenza and Matera; \\ SALVATORE D'ANGELO, MD, \\ Researcher, \\ Rheumatology Department of Lucania, \\ San Carlo Hospital of Potenza and Madonna \\ delle Grazie Hospital of Matera, \\ Potenza and Matera; \\ and University of Molise, \\ Campobasso; \\ CARLO PALAZZI, MD, \\ Senior Investigator; \\ PIETRO LECCESE, MD, \\ Researcher; \\ ANGELA PADULA, MD, \\ Senior Registrar, \\ Rheumatology Department of Lucania, \\ San Carlo Hospital of Potenza and Madonna \\ delle Grazie Hospital of Matera, \\ Potenza and Matera, Italy
}

Address correspondence to Dr. Olivieri.

E-mail: ignazioolivieri@tiscalinet.it

\section{REFERENCES}

1. Amor B, Dougados M, Mijiyawa M. Criteria of the classification of spondylarthropathies [French]. Rev Rhum Mal Osteoartic 1990;57:85-9.

2. Dougados M, van der Linden S, Juhlin R, Huitfeldt B, Amor B, Calin A, et al. The European Spondylarthropathy Study Group preliminary criteria for the classification of spondylarthropathy. Arthritis Rheum 1991;34:1218-27. 
3. Toussirot E, Wendling D. Late-onset ankylosing spondylitis and related spondylarthropathies: Clinical and radiological characteristics and pharmacological treatment options. Drugs Aging 2005;22:451-69.

4. Olivieri I, Pipitone N, D’Angelo S, Padula A, Salvarani C. Late-onset rheumatoid arthritis and late-onset spondyloarthritis. Clin Exp Rheumatol 2009;27 Suppl 55:S139-45.

5. van der Linden S, Valkenburg HA, Cats A. Evaluation of diagnostic criteria for ankylosing spondylitis. A proposal for modification of the New York criteria. Arthritis Rheum 1984;27:361-8.

6. Carbone LD, Cooper C, Michet CJ, Atkinson EJ, O'Fallon WM, Melton LJ 3rd. Ankylosing spondylitis in Rochester, Minnesota, 1935-1989. Is the epidemiology changing? Arthritis Rheum 1992;35:1476-82.

7. Feldtkeller E, Bruckel J, Khan MA. Scientific contributions of ankylosing spondylitis patient advocacy groups. Curr Opin Rheumatol 2000;12:239-47.

8. Brophy S, Calin A. Ankylosing spondylitis: interaction between genes, joints, age at onset, and disease expression. J Rheumatol 2001;28:2283-8.

9. Calin A, Elswood J, Edmunds L. Late onset ankylosing spondylitis - A distinct disorder? Br J Rheumatol 1991;30:69-70.

10. Montilla C, Del Pino-Montes J, Collantes-Estevez E, Font P, Zarco $\mathrm{P}$, Mulero J, et al. Clinical features of late-onset spondylitis: Comparison with early-onset disease. J Rheumatol 2012;39:1008-12.

11. Dubost JJ, Sauvezie B. Late onset peripheral spondyloarthropathy. J Rheumatol 1989;16:1214-7.

12. McCarty DJ, O’Duffy JD, Pearson L, Hunter JB. Remitting seronegative symmetrical synovitis with pitting edema. RS3PE syndrome. JAMA 1985;254:2763-7.

13. Dubost JJ, Ristori JM, Zmantar C, Sauvezie B. Seronegative rheumatism of late onset. Incidence and atypical forms of spondylarthropathy [French]. Rev Rhum Mal Osteoartic 1991;58:577-84.

14. Olivieri I, Oranges GS, Sconosciuto F, Padula A, Ruju GP, Pasero G. Late onset peripheral seronegative spondyloarthropathy: Report of two additional cases. J Rheumatol 1993;20:390-3.

15. Olivieri I, Padula A, Pierro A, Favaro L, Oranges GS, Ferri S. Late onset undifferentiated seronegative spondyloarthropathy. J Rheumatol 1995;22:899-903.

16. Olivieri I, Padula A, Ciancio G, Cantini F, Salvarani C, Gonzalez-Gay MA. Late onset HLA-B27-positive undifferentiated spondyloarthropathy: A new series of 20 patients [abstract]. Arthritis Rheum 2001;44 Suppl:S94.

17. Olivieri I, Garcia-Porrua C, Padula A, Cantini F, Salvarani C, Gonzalez-Gay MA. Late onset undifferentiated spondyloarthritis presenting with polymyalgia rheumatica features: Description of seven cases. Rheumatol Int 2007;27:927-33.

18. Rudwaleit M, van der Heijde D, Landewé R, Listing J, Akkoc N, Brandt J, et al. The development of Assessment of Spondyloarthritis international Society classification criteria for axial spondyloarthritis (Part II): Validation and final selection. Ann Rheum Dis 2009;68:777-83.

19. Rudwaleit M, van der Heijde D, Landewé R, Akkoc N, Brandt J, Chou CT, et al. The Assessment of SpondyloArthritis Internationa Society classification criteria for peripheral spondyloarthritis and for spondyloarthritis in general. Ann Rheum Dis 2011;70:25-31.

20. Braun J, van der Berg R, Baraliakos X, Boehm H, Burgos-Vargas R, Collantes-Estevez E, et al. 2010 update of the ASAS/EULAR recommendations for the management of ankylosing spondylitis. Ann Rheum Dis 2011;70:896-904.

First Release May 15 2012; J Rheumatol 2012;39:1110-12; doi:10.3899/jrheum.120184 